\title{
International Society of Nephrology-Hydration and Kidney Health Initiative - Expanding Research and Knowledge
}

\author{
Louise M. Moista, b William F. Clark ${ }^{a, b} \quad$ Luca Segantini $^{d} \quad$ Sandrine Damster $^{d}$ \\ Laurent Le Bellego ${ }^{e}$ Germaine Wong ${ }^{f}$ Marcello Tonellic ${ }^{c}$ \\ ${ }^{a}$ Schulich School of Medicine and Dentistry, Western University, and ${ }^{b}$ Kidney Clinical Research Unit, London \\ Health Sciences Center and Lawson Health Research Unit, London, Ont., and ' Department of Medicine, University

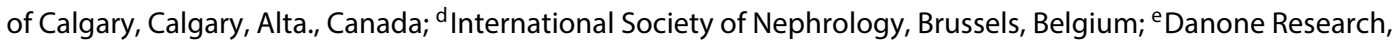 \\ Palaiseau, France; fSydney School of Public Health, University of Sydney, Centre for Transplant and Renal Research, \\ Sydney, Australia
}

\section{Key Words}

Hydration · Kidney health · New investigator · International Society of Nephrology · Water

\begin{abstract}
The purpose of this manuscript is to describe a collaborative research initiative to explore the role of hydration in kidney health. Our understanding of the effects of hydration in health and disease is surprisingly limited, particularly when we consider the vital role of hydration in basic human physiology. Recent initiatives and research outcomes have challenged the global medical community to expand our knowledge about hydration, including the differences between water, sugared beverages and other consumables. Identification of the potential mechanisms contributing to the benefits of hydration has stimulated the global nephrology community to advance research regarding hydration for kidney health. Hydration and kidney health has been a focus of research for several research centers with a rapidly expanding world literature and knowledge. The International Society of Nephrology has collaborated with Danone Nutricia Research to promote development of kidney research initiatives, which focus on the role of hydration in kidney health and the
\end{abstract}

\section{KARGER}

E-Mail karger@karger.com www.karger.com/anm

\section{(c) 2016 The Author(s) \\ Published by S. Karger AG, Basel 0250-6807/16/0686-0032\$39.50/0}

This article is licensed under the Creative Commons Attribution NonCommercial-NoDerivatives 4.0 International License (CC BYNC-ND) (http://www.karger.com/Services/OpenAccessLicense) Usage and distribution for commercial purposes as well as any distribution of modified material requires written permission. global translation of this new information. This initiative supports the use of existing data in different regions and countries to expand dialogue among experts in the field of hydration and health, and to increase scientific interaction and productivity with the ultimate goal of improving kidney health.

(C) 2016 The Author(s)

Published by S. Karger AG, Basel

\section{Introduction}

The number of people affected by chronic kidney disease (CKD) and end-stage kidney disease (ESKD) is increasing worldwide. The main strategy for reducing the risk of developing ESKD and associated cardiovascular diseases is 2-fold: (1) improve the early detection of CKD and (2) identify modifiable factors to reduce the progression of CKD. Recent studies have identified an association between fluid intake, urinary markers and kidney function in the general population [1-3]. Presently, ongoing randomized controlled trials are studying the effects of hydration state on kidney health but they are limited to certain populations and levels of kidney function [4]. Randomized controlled, cohort controlled and obser- 
vational studies that address diverse questions frequently have large validated databases, represent global populations, and contain data on kidney function and some measure of hydration (fluid intake, urine volume, osmolality, sodium). Promotion and support for use of these data to study the effect of hydration on health will broaden our awareness and knowledge of the effects of hydration on kidney health.

Danone Nutricia Research and the International Society of Nephrology (ISN) have collaborated to create the Hydration for Kidney Health $(\mathrm{H} 4 \mathrm{KH})$ research initiative, to stimulate established and new researchers to explore the role of hydration in kidney health. A Steering Committee was established to provide leadership in establishing terms of reference, format of research initiatives and review of research applications and to provide advice pertaining to award competitions including policies, practices and funding. Additionally, the Steering Committee will monitor the future progress of $\mathrm{H} 4 \mathrm{KH}$ program awardees and initiatives and recommend continuation or expansion of the $\mathrm{H} 4 \mathrm{KH}$ initiative. The Chair was appointed by the ISN and members included experienced researchers with expertise in CKD and or related diseases, use of administrative data bases, collaborative research, who had an interest in $\mathrm{H} 4 \mathrm{KH}$ and who represented different global regions. The Steering Committee members included L.M. Moist (Chair), Marcello Tonelli, ISN Chair of Research, W.F. Clark (Canada), Germaine Wong (Australia), Luca Segantini, ISN Executive Director and L. Le Bellego (Danone Nutricia Research, non-voting member), with ISN support from Sandrine Damster.

The objectives of the $\mathrm{H} 4 \mathrm{KH}$ initiative are to enhance awareness and knowledge of the effects of hydration on kidney health, expand scientific evidence, expand research capacity by supporting new investigators who focus on preventing CKD, engage researchers in the development of transdisciplinary research networks and create sustainable research momentum.

Two research opportunities were initiated. Both were directed toward applicants from all disciplines relevant to kidney disease (i.e., clinical, health services, population health disciplines). The first opportunity was to support new investigators who were within the first 5 years of initial faculty appointment and who held a MD and/or $\mathrm{PhD}$ degree. The individuals must have demonstrated excellence during pre-doctoral and post-doctoral training in kidney disease and a research interest in $\mathrm{H} 4 \mathrm{KH}$. The successful applicants agreed to devote 12 months working in the Kidney Clinical Research Unit in London, Ontario
(Canada), gain exposure and skill in clinical research and statistical analysis and begin work on research project(s) related to $\mathrm{H} 4 \mathrm{KH}$. Applicants also agreed to devote a second year in their home institution, completing their research and building infrastructure support for further research in hydration. Evaluation criteria included previous research, independent thinking and the integration of newly learned skills into the applicant's future plans for hydration research. This new investigator award provides support of $\$ 70,000$ US over 2 years. In the first year, the new investigator is awarded a maximum of $\$ 45,000$ US to offset expenses related to travel, accommodations and living expenses. In the second year, a maximum of $\$ 25,000$ US is available to support the research and build infrastructure at the home institution.

The second research opportunity involves the Hydration and Kidney Health Grant. This program supports an investigator with expertise in, and access to, a reliable and valid existing database; these data reflect a representative sample of the general population and/or a population with CKD, including demographics, comorbidities and serial measures of kidney function. The successful applicant is awarded $\$ 25,000$ US per year for a maximum of 2 years. Both applicants agree to present research progress/results at the World Congress of Nephrology 2017 and submit a paper to a peer reviewed journal.

The call for research applicants was made through the ISN website http://www.theisn.org/initiatives/h4khresearch-initiative [5]. During the initial year, these programs were highly successful with 8 applications applying for the 2 grants. The Steering Committee assessed and selected the applications based on a priori criteria and granting rules.

\section{Successful Candidates}

Dr. Fabiana Nerbass, from the Fundação Pró-Rim in Joinville, Brazil will receive the initial New Investigator Grant for her project entitled Kidney Health in Brazilian Industrial Workers Exposed to Heat Stress and Dehydration. Dr. Nerbass will start her work on this project in London Canada in the summer of 2016. Dr. Sofia Enhörning, from Skåne University Hospital in Malmö, Sweden will receive the initial Hydration and Kidney Health Grant for her project entitled 'Plasma Copeptin and Copeptin-associated loci as Predictors of Cardiorenal Disease'. She will incorporate population-based prospective cohort studies and a Mendelian randomization approach. 
The ISN-H4KH research initiative bridges disciplines and overcomes geographical distances, to establish strong research networks that improve the health of people with kidney disease. We congratulate the successful applicants and anticipate rewarding experiences and new research findings.

\section{References}

1 Clark WF, Sontrop JM, Macnab JJ, et al: Urine volume and change in estimated GFR in a community-based cohort study. Clin J Am Soc Nephrol 2011;6:2634-2641.

\section{Disclosure Statement}

L.M.M. received consultant fees from Danone Research. W.F.C. received consultant fees and research grant funding from Danone Research. L.L.B. is a full-time employee of Danone Research. L.S., S.D., G.W. and M.T. have no financial interests to declare.
2 Sontrop JM, Dixon SN, Garg AX, et al: Association between water intake, chronic kidney disease, and cardiovascular disease: a crosssectional analysis of NHANES data. Am J Nephrol 2013;37:434-442.

3 Palmer SC, Wong G, Iff S, et al: Fluid intake and all-cause mortality, cardiovascular mortality and kidney function: a populationbased longitudinal cohort study. Nephrol Dial Transplant 2014;29:1377-1384.
4 Clark WF, Sontrop JM, Huang SH, et al: The chronic kidney disease water intake trial (WIT): results from the pilot randomised controlled trial. BMJ Open 2013;3:e003666.

5 http://www.theisn.org/initiatives/h4kh-research-initiative (accessed March 27, 2016). 